\title{
A CRIATIVIDADE DO EXCESSO: EFEITOS DA SOBRECARGA DE INFORMAÇÃO SOBRE A CIÊNCIA DA INFORMAÇÃO
}

\author{
THE CREATIVITY OF EXCESS: THE INFLUENCE OF \\ INFORMATION OVERLOAD ON INFORMATION SCIENCE
}

\author{
Duanne de Oliveira Ribeiro \\ Marivalde Moacir Francelin
}

Resumo: Esta pesquisa discute o conceito de sobrecarga de informação - seus aspectos constitutivos -, bem como as condições sociais em que surge essa problemática. Por meio do debate conceitual, observa-se a relação da sobrecarga com termos similares, entre outros, explosão da informação e caos documentário, e se afirma que as condições de possibilidade da sobrecarga são uma certa concepção de tarefa e uma avaliação de recursos disponíveis. A partir de uma análise histórica, notam-se ocorrências da sobrecarga da Antiguidade à contemporaneidade, em que o modo como os sujeitos ligados à criação do conhecimento percebem a sobrecarga é semelhante. Ainda mais, essa perspectiva permite ver que o fenômeno, para além das suas consequências negativas, pode ser o disparador da invenção de novas técnicas e sistemas que visam a combatê-lo, situação que pode se apontar em alguns momentos de mudança paradigmática da Ciência da Informação.

Palavras-chave: Sobrecarga de Informação. Explosão da Informação. História da Ciência da Informação.

\begin{abstract}
Esta pesquisa discute o conceito de sobrecarga de informação - seus aspectos constitutivos - bem como as condições sociais em que surge essa problemática. Por meio do debate conceitual, observa-se a relação da sobrecarga com termos similares, entre outros, explosão da informação e caos documentário, e se afirma que as condições de possibilidade da sobrecarga são uma certa concepção de tarefa e uma avaliação de recursos disponíveis. A partir de uma análise histórica, notam-se ocorrências da sobrecarga da Antiguidade à contemporaneidade, em que o modo como os sujeitos ligados à criação do conhecimento percebem a sobrecarga é semelhante. Ainda mais, essa perspectiva permite ver que o fenômeno, para além das suas consequências negativas, pode ser o disparador da invenção de novas técnicas e sistemas que visam a combatê-lo, situação que pode se apontar em alguns momentos de mudança paradigmática da Ciência da Informação.
\end{abstract}

Keywords: Tradução das palavras-chave em inglês, apresentadas em ordem alfabética.

\section{Introdução}

O estudo da sobrecarga de informação circunscreve uma situação de crise nos processos de criação, coleta, transformação, disponibilização e armazenamento do conhecimento. Esse fenômeno se refere, de maneira geral, à circunstância em que os sujeitos ou grupos dedicados ao uso ou tratamento de uma quantidade de informação (cujo valor é definido por preceitos socioculturais ou profissionais) se veem incapacitados para cumprir os seus objetivos, por limitações de tempo e/ou capacidade de trabalho. Assim, a problemática é capaz de abranger o excesso de estímulos sensoriais (por exemplo, em grandes cidades); a 
VI Seminário de Pesquisa em Ciência da Informação do PPGCI 2017

Escola de Comunicações e Artes - Universidade de São Paulo

absorção de conteúdo midiático; a incapacidade para escolher causada pelo exagero de opções; a invisibilização de dados relevantes, perdidos no todo; as consequências de um maior fluxo informacional nas redes de produção do saber (como no campo das pesquisas científicas).

Com base em um estudo de diversas definições do fenômeno, Jackson e Farzaneh (2012, p. 11) formulam um modelo da sobrecarga de informação com três elementos base: informação, indivíduo e tarefa. A ocorrência e a intensidade do fenômeno seriam determinadas por estes fatores: quantidade de informação, características da informação (“complexidade, ambiguidade, incerteza, novidade"), qualidade da informação ("relevância e validade"), capacidade de processamento de informação, tempo disponível, tarefa e parâmetros do processamento e fatores pessoais. Em cada caso, a configuração de níveis variados das unidades posiciona o sujeito em um contínuo não-sobrecarregado <-> sobrecarregado.

A abordagem multifacetada de Jackson e Farnazeh indica que não é a disponibilidade de informação por si, ou as quantidades brutas de dados, que implicam a sobrecarga. Trata-se de uma relação sujeito-informação determinada pelo contexto. Com frequência, vê-se textos que enunciam o crescimento da publicação de conteúdo ou o número crescente de bits presente na internet como sinais de que estaríamos submetidos a um excesso jamais visto. É certo que as condições informacionais de hoje não têm precedentes; mas temos de avaliar essas quantias pelo que representam aos indivíduos e grupos que têm de lidar com elas, como os sujeitos as interpretam e que recursos possuem para tratá-las.

\section{Historicidade da Sobrecarga e Ciência da Informação}

Outra evidência de que é preciso pensar o crescimento da informação de acordo com os seus contextos socioculturais é o fato de que em diversos momentos da história sujeitos se perceberam sobrecarregados — Rosenberg (2003, p. 1-2) fala de uma "retórica da novidade" quanto a esses fenômenos. Podemos perceber essa historicidade da sobrecarga de informação por meio de trabalhos como o de Blair (2010), que estuda manifestações do tipo do século XVI aos XVIII. Os objetos de estudo da pesquisadora são as obras de referência antologias, dicionários, enciclopédias - pelas quais se percebe como os profissionais do conhecimento lidavam com as demandas informacionais do seu tempo. Sob a pressão da sobrecarga, os autores desenvolviam novas posturas em relação à erudição, das quais duas se destacam: ou eles pretendiam abranger panoramicamente, por meio de trechos, a multiplicidade publicada, ou estabeleciam critérios de qualidade que restringiam a sua 
VI Seminário de Pesquisa em Ciência da Informação do PPGCI 2017

Escola de Comunicações e Artes - Universidade de São Paulo

necessidade intelectual ao cânone. Além disso, criavam novos meios para dispor os textos nas páginas, guiando de maneira mais objetiva a leitura. As práticas desses profissionais descortinadas por Blair anunciam as que podemos enxergar até os dias de hoje.

É particularmente interessante perscrutar esse caráter histórico da sobrecarga no que se refere à Ciência da Informação. Em pioneiros do campo - tomando-o de forma lata vemos a preocupação com situações de excesso informacional, embora as nomeiem com outros termos. Seria o caso da "multidão de livros" denunciada por Conrad Gesner, "pai da bibliografia", cujo projeto de organização do conhecimento foi incitado pela irritação e falta de sentido causados pelo problema (ARAÚJO; CRIPPA, 2016). Também Paul Otlet, em um texto fundador da Documentação, fala de circunstâncias do tipo:

[...] os Livros e os Documentos. Expressões escritas das ideias, instrumentos da sua fixação, da sua conversação, da sua circulação, são os intermediários obrigatórios de todas as relações entre os Homens. A sua massa enorme, acumulada no passado, se acresce a cada dia, a cada hora, de novas unidades em número desconcertante, por vezes alucinante. Deles, como da Língua, pode-se dizer que é possível surgir o pior e o melhor das coisas. Deles, como da água que cai do céu, pode-se dizer que advêm inundação e dilúvio ou que se espalha em chuva benfazeja. (OTLET, 1934, p. 4, tradução nossa)

No início da primeira metade do século XX, quando é publicado As We May Think, de Vannevar Bush, texto considerado um marco da criação da Ciência da Informação, está também em funcionamento os efeitos da sobrecarga:

Bush fez duas coisas: a) ele sucintamente definiu um problema crítico e estratégico que estava na mente de muitos, e b) propôs uma solução que era um 'corretivo tecnológico', e dessa forma estava afinado com o espírito do tempo. Ambas tinham grande apelo e Bush foi ouvido por causa do seu status intelectual. Ele definiu o problema em termos quase poéticos, 'a massiva tarefa de tornar mais acessível uma desnorteante reserva de conhecimento'. Em outras palavras, Bush abordou o problema da explosão de informação. O problema ainda está conosco. A solução dele foi usar a computação que surgia no período e outras tecnologias da informação para combater o problema. (SARACEVIC, 1999, p. 1053, grifo nosso)

Esse pequeno percurso pela história da Ciência da Informação — pelos pensamentos de Gesner, Otlet e Bush - nos deixa ver de forma sucinta como, no modo como tais textos definem o seu problema de origem, se vê a analogia com a sobrecarga de informação. $O$ imbróglio de uma quantidade excessiva de dados, com efeito, os levou a desenvolver as teorias e técnicas que marcam a sociedade desde então. Nisso, enxergamos a declaração seguinte de Neill (1992, p. 100): “Cheguei à conclusão de que, claro, para bibliotecários e cientistas da informação, a sobrecarga de informação era uma oportunidade, um desafio, uma chance de fazer o que fazem melhor”. Um espaço aberto à criatividade. 
VI Seminário de Pesquisa em Ciência da Informação do PPGCI 2017

Escola de Comunicações e Artes - Universidade de São Paulo

\section{Conclusão}

A partir do material apresentado é difícil sustentar que a sobrecarga seja um fenômeno exclusivo do século XXI, por mais distinto que seja esse ambiente informacional gerado pela internet e pelas novas mídias. Com tal aprendizado, podemos nos abrir a um retorno ao trabalho dos séculos anteriores, procurando entender os modos como confrontaram a problemática da grande quantidade e velocidade da informação - a cada vez única, porém semelhante na percepção e forma - de modo a entender e reagir aos desafios da atualidade consistentemente.

\section{Referências}

ARAÚJO, André Vieira de Freitas; CRIPPA, Giulia. Confusa e irritante multidão de livros: relações entre o contexto histórico-informacional da Europa moderna e a estrutura documentária de bibliotheca universalis, de Conrad Gesner. Incid: Revista de Ciência da Informação e Documentação, v. 7, n. esp., p. 224-241, 2016.

BAWDEN, David; HOLTHAM, Clive; COURTNEY, Nigel. Perspectives on Information Overload. Aslib Proceedings, v. 51. n. 8, p. 249-255, 1999.

BLAIR, Ann. Too much to know - Managing scholarly information before the Modern Age. New Haven: Yale University, 2010.

BLOM, Fredrik. Information Overload and the growing infosphere: a comparison of the opinions and experiences of information specialists and general academics on the topic of Information Overload. 2011. Dissertação (Mestrado em Biblioteconomia e Ciência da Informação) - Uppsala Universitet.

JACKSON, Thomas. e FARZANEH, Pourya. Theory-based model of factors affecting information overload. International Journal of Information Management, $n^{0} 32$ (6), p. 1 23. Disponível em: https://dspace.lboro.ac.uk/dspace-jspui/handle/2134/11702. Último acesso em: 8 out. 2016.

NEILL, Samuel D. The Dilemma of Information Overload: Managing in the Information Society. In: Dilemmas in the study of Information: exploring the boundaries of Information Science. Westport: Greenwood Press, 1992. p. 99-158.

OTLET, Paul. Traité de documentation — Le livre sur le livre. Bruxelas: Editiones Mundaneum, 1934. Disponível em:

$<$ http://lib.ugent.be/fulltxt/handle/1854/5612/Traite de documentation ocr.pdf $>$. Acesso em: 10 jul. 2016.

ROSENBERG, Daniel. Early Modern Information Overload. Journal of the History of Ideas, v. 64, n. 1, p. 1-9, jan. 2003.

SARACEVIC, Tefko. Information Science. Journal of the American Society for Information Science, v. 50, n. 12, p. 1051-1063, 1999. Disponível em:

$<$ https://comminfo.rutgers.edu/ tefko/JASIS1999.pdf> $>$. Acesso em: 9 ago. 2015. 
VI Seminário de Pesquisa em Ciência da Informação do PPGCI 2017

Escola de Comunicações e Artes - Universidade de São Paulo

TIDLINE, Tonyia J. The Mythology of Information Overload. Library Trends, v. 47, n. 3, p. 485-505, 1999. Disponível em:

$<$ https://www.ideals.illinois.edu/bitstream/handle/2142/8235/librarytrendsv47i31_opt.pdf?seq uence $=1>$. Acesso em: 14 jul. 2016.

\section{Sobre os autores}

Duanne de Oliveira Ribeiro

Jornalista. Mestre em Ciência da Informação pela Escola de Comunicação e Artes da Universidade de São Paulo.

Marivalde Moacir Francelin

Professor doutor do Departamento de Informação e Cultura da Escola de Comunicação e Artes da Universidade de São Paulo. 